\title{
Problematizações acerca do gênero do discurso história em quadrinhos não ficcional
}

\author{
Problematizations about gender of discourse in nonfiction
}

\author{
comics
}

\author{
Mayara Barbosa Tavares*
}

\begin{abstract}
RESUMO: A pesquisa objetiva a análise e a problematização do gênero do discurso história em quadrinhos não ficcional intitulada $O$ incrível mensalão, de Angeli, veiculada no Jornal Folha de São Paulo, em 2012. A fundamentação teórica liga-se às obras de Bakhtin $(2003,2006)$ e a noção de gênero do discurso e outras. Para a teorização das histórias em quadrinhos, são utilizadas as obras de Eisner (2001, 2005), com foco nos conceitos de arte sequencial e narrativa gráfica; e de Ramos (2009a, 2009b), com as contribuições sobre a linguagem dos quadrinhos. É perceptível o uso do gênero do discurso história em quadrinhos para a abordagem de assuntos não ficcionais, como o caso do mensalão. As características que corroboram para o uso da história em quadrinhos não ficcional são a utilização da linguagem verbal e não verbal, a relação entre as forças centrípetas e centrífugas do gênero e a crescente aceitação do gênero na sociedade atual.
\end{abstract}

PALAVRAS-CHAVES: Quadrinhos. Não ficcional. Gênero do Discurso.

ABSTRACT: This research aims to analysis and questioning of gender discourse in nonfiction comics entitled $O$ incrível mensalão, of Angeli, conveyed in the newspaper Folha de São Paulo, in 2012. The theoretical foundation is bound to works of Bakhtin $(2003,2006)$ and the notion of gender discourse and others. For the theory of comics, Eisner's works are used (2001, 2005), focusing on the concepts of sequential art and graphic narrative; and Ramos (2009a, 2009b), with contributions about the language of comics. It is noticeable the use of speech story genre in comics to the approach of nonfiction topics, such as the case of the mensalão. Features that support the use of history in nonfiction comics are the use the verbal and non-verbal language and the relationship between centripetal and centrifugal forces of the genre and the growing acceptance of gender in today's society.

KEYWORDS: Comics. Nonfiction. Gender discourse.

\footnotetext{
* Doutoranda em Letras e Linguística (UFG), mestra em Letras e Linguística (UFG), graduada em Letras/Português (UFG). E-mail: mayarabtav@hotmail.com.
} 


\section{Introdução}

Atualmente, é perceptível o crescente uso das histórias em quadrinhos para veicular temáticas relacionadas à política, aos movimentos sociais, dentre outros. Fato que nos motiva a questionar o porquê do uso constante dos quadrinhos para expressar assuntos não ficcionais. Para refletir sobre esse uso optamos por analisar a história em quadrinhos não ficcional intitulada $O$ incrível mensalão, de Angeli, veiculada em meio impresso e digital no Jornal Folha de São Paulo, no dia 19 de agosto de 2012 (CARVALHO, 2012).

Dentre as pesquisas já realizadas com relação à temática, tem-se o trabalho de Viana (2011) que relaciona os quadrinhos e a política ao afirmar que os quadrinhos são produtos sociais e na sociedade contemporânea tudo carrega a marca da política, definida como toda forma de manifestação da luta de classes ou relações de poder. Há também o artigo de Pires (2006), que explicita nos quadrinhos Fradim, de Henfil, a constatação do esforço de resistência e a contribuição dos quadrinhos para a luta política contra a ditadura militar. E o artigo de Fernandes (2010), que problematiza, a partir dos elementos visuais, a construção das personagens ficcionais e não ficcionais das histórias em quadrinhos de Maurício de Sousa.

A partir desse levantamento bibliográfico, podemos verificar, dentre as investigações acerca da temática proposta, a inexistência de uma pesquisa que analise $O$ incrível mensalão, de Angeli, e problematize o porquê da escolha do gênero do discurso história em quadrinhos não ficcional, com embasamento teórico nas obras de Bakhtin $(2003,2006)$ e os conceitos de interação verbal, gêneros do discurso, ideologia do cotidiano, dentre outros. E de Eisner (2001, 2005) e suas noções de arte sequencial e narrativa gráfica, dentre outros autores que teorizam acerca dos quadrinhos.

Optamos pela construção de uma pesquisa de cunho qualitativo, pois, segundo Denzin e Lincoln (2006), trata de um campo interdisciplinar que atravessa as ciências humanas e sociais. A pesquisa qualitativa é vista como um 
conjunto de atividades interpretativas, com foco multiparadigmático, que possibilita aos seus praticantes um compromisso com a perspectiva naturalista e com a compreensão interpretativa da experiência humana.

No processo da pesquisa qualitativa, "cada pesquisador fala a partir de uma comunidade interpretativa distinta que configura, em seu modo especial, os componentes multiculturais, marcados pelo gênero, do ato da pesquisa" (DENZIN; LINCOLN, 2006, p. 32). Ou seja, as análises do gênero do discurso história em quadrinhos não ficcional, durante o processo de pesquisa, são embasadas na teoria bakhtiniana sobre gêneros do discurso e na teoria das histórias em quadrinhos e, também, são marcadas pelas experiências sociais, culturais e ideológicas individuais, o que confere aos estudos certa particularidade.

Para a realização das análises é utilizada a metodologia de análise de documentos. Um documento, em consonância com Duffy (2008), é uma impressão deixada em um objeto físico, por um ser humano, como fotografias, textos, vídeos ou história em quadrinhos, sendo essa última o corpus para o nosso estudo, definida como um tipo de documento de mídia, publicada em sites e/ou revistas, gibis.

Partimos, na sequência, para a explicitação de alguns pontos essenciais relativos ao gênero do discurso e à história em quadrinhos.

\section{Gêneros do discurso}

Para refletirmos sobre os gêneros do discurso é necessário estabelecermos algumas considerações sobre o texto. Em consonância com Koch (2009, p. 13), "a concepção de sujeito da linguagem varia de acordo com a concepção de língua que se adote" e, consequentemente, ambas interferem na concepção de texto.

Se concebermos a língua como representação do pensamento tem-se o sujeito psicológico, dono de suas vontades e ações, e para tal, o texto é visto 
como um produto lógico do pensamento do autor e resta apenas ao leitor/ouvinte captar essa representação, fato esse que configura um papel passivo por parte do receptor/leitor do texto.

Se adotada a concepção de língua como estrutura, como código, vista apenas como mero instrumento de comunicação, o texto é visto como simples produto dessa codificação, em que o leitor/ouvinte deve apenas decodificar o transposto pelo emissor, logo, a concepção de sujeito se dá em torno do assujeitamento, na qual o indivíduo não é dono de seu dizer e de sua vontade.

$\mathrm{Na}$ concepção de língua como lugar de interação, com a qual nos identificamos, os sujeitos atuam como construtores sociais e, por conseguinte, o texto é considerado como o lugar da interação e os interlocutores como sujeitos ativos que nele se constroem e são construídos, dialogicamente. Destarte, a partir dessa acepção, Koch (2009, p. 20) define o texto como um "evento dialógico (Bakhtin), de interação entre os sujeitos sociais contemporâneos ou não, co-presentes ou não, do mesmo grupo social ou não, mas em diálogo constante" e, em decorrência, é por meio da interação entre o texto e os sujeitos que os sentidos do texto são construídos. Temos assim, alguns apontamentos para iniciarmos a compreensão da noção de gênero do discurso, de Bakhtin.

A partir da translinguística, que tem como objeto de estudo os enunciados, tem-se a análise translinguística das unidades linguísticas transfrásticas, que objetiva, segundo Fiorin (2010), analisar as significações do texto e, principalmente, examinar as relações com o que está fora dele. Logo, na translinguística, problematizada por Bakhtin, o discurso é também o objeto de análise, pois o discurso é um objeto integralmente linguístico, integralmente histórico e é dialógico, por sua relação permanente com outros discursos dialogismo. Conforme Fiorin (2010), a análise translinguística é a análise do modo de funcionamento real da linguagem, o que significa a análise da historicidade do discurso, do processo social, histórico e ideológico de constituição dos sentidos. Em consonância com Faïta (2005), para Bakhtin o 
discurso é visto como uma multiplicidade de sistemas de crenças verbais, ideológicas e sociais interligadas.

A teoria construída pelo filósofo russo Bakhtin é pautada, dentre outros aspectos, nas críticas direcionadas ao objetivismo abstrato realizado por Saussure e ao subjetivismo individualista. Em linhas gerais, para Saussure (1977), a linguagem é multiforme e heteróclita e origina-se da dicotomia língua (langue) e fala (parole). Saussure foca seus estudos sobre a língua, que é vista como um sistema de signos que se constitui através de regularidades (convenções e normas). Já a fala é resultado de combinações individuais e, por sua complexidade devido às escolhas voluntárias dos falantes, não é abordada com profundidade nos estudos saussurianos, fato que contribui para as críticas de Bakhtin ao objetivismo abstrato.

Bakhtin (2006) explicita que a língua vive e evolui historicamente na comunicação verbal concreta, não no sistema linguístico abstrato das formas da língua (objetivismo abstrato) nem no psiquismo individual dos falantes (subjetivismo individualista). Assim, a verdadeira substância da língua é constituída pelo fenômeno social da interação verbal, realizada por meio da enunciação ou das enunciações. Para o autor, a palavra é produto da interação, pois, procede de alguém (locutor) para alguém (interlocutor). Uma mesma palavra pode possuir vários sentidos e entoações segundo a situação e 0 contexto social de inserção dos falantes. A palavra é constituída por leis sociológicas e ideológicas.

Assim, as críticas feitas por Bakhtin (2006) ao objetivismo abstrato, com foco nas obras de Saussure, explicitam a constituição da teoria bakhtiniana. Têm-se reflexões sobre a relação interativa entre locutor e interlocutor; a importância da situação e do contexto para a construção de sentidos variados; a diferença entre compreender e identificar; o signo é variável e flexível; a língua é viva e, por isso, não deve ser estudada como língua morta ou estrangeira ao falante; a palavra é carregada de um conteúdo ou sentido ideológico ou vivencial e seu sentido é totalmente determinado por 
seu contexto; a enunciação é de natureza social e é uma resposta a alguma coisa.

Destarte, para Bakhtin (2006), todo signo é ideológico e sem signos não existe ideologia. O signo reflete e refrata a realidade. A ideologia é vista como cotidiana, valorativa, isto é, a ideologia não possui apenas uma conotação política, mas também aspectos relacionados ao social, ao histórico, ao cultural, ao que é considerado justo/injusto, certo/errado, bom/ruim e outros. É perceptível que o significado não é dado previamente, pois é construído a partir das ideologias. Como assinala Bakhtin (2006, p. 67), "cada palavra se apresenta como uma arena em miniatura onde se entrecruzam e lutam os valores sociais de orientação contraditória".

De acordo com Bakhtin (2003), todos os variados campos da atividade humana encontram-se ligados ao uso da linguagem. Isto é, o ser humano, o sujeito, inserido nos diversos contextos - familiar, profissional, acadêmico, amoroso, dentre outros -, interage com outros sujeitos e consigo próprio via linguagem, seja ela verbal ou não verbal. Para Bakhtin (2006), a interação verbal está vinculada às condições de uma situação social, cada época e cada grupo social têm seu repertório de formas de discurso na comunicação socioideológica. Fato que não contradiz, conforme as concepções bakhtinianas, a unidade nacional de uma língua. A língua é vista como uma atividade essencialmente dialógica, na qual os sujeitos interagem em dados momentos sociais, históricos e ideológicos.

Em consonância com Bakhtin (2003, 2006), o emprego da língua realiza-se em forma de enunciados ${ }^{1}$ concretos, únicos e não reiteráveis, que podem ser orais ou escritos, proferidos pelos integrantes dos diversos campos da atividade humana. Os enunciados pressupõem a alternância dos sujeitos; a atitude responsiva, as réplicas; o autor é inserido na realidade imediata; é marcado pela exauribilidade, com efeito de final, o sentido é pleno no contexto; e possui uma estabilidade relativa. Para Bakhtin (2003), os enunciados

\footnotetext{
${ }^{1}$ No transcorrer de suas obras, Bakhtin $(2003,2006)$ não faz distinções entre enunciado e enunciação.
} 
refletem as condições específicas e as finalidades de cada um dos campos da atividade humana, por meio do conteúdo temático (o tema), do estilo (as escolhas feitas pelo sujeito) e da construção composicional (o aspecto formal, as funções do texto).

Estes três elementos - conteúdo temático, estilo e construção composicional - encontram-se indissoluvelmente associados ao todo do enunciado e, por isso, são igualmente determinados pelas peculiaridades dos variados campos da atividade humana, da comunicação. Campos que elaboram seus tipos relativamente estáveis de enunciados, os denominados gêneros do discurso.

Portanto, para Bakhtin (2003, p. 262), gêneros do discurso são "tipos relativamente estáveis de enunciados". O que significa afirmar que os gêneros são dinâmicos, no sentido, de serem moldáveis pelos interlocutores inseridos em dados contextos sociais, históricos e ideológicos, e que possuem também características/formas predominantes, pré-estabelecidas historicamente, por meio de convenções linguísticas e/ou literárias, que permitem a identificação e a percepção de dadas peculiaridades frente à heterogeneidade de gêneros existentes na sociedade.

Ao verificarmos sua característica relativamente estável, é possível interpretarmos que o que constitui um gênero não são apenas seus aspectos formais, mas também a sua ligação, a sua conexão, com uma situação social de interação, haja vista que para nós a língua é concebida como o lugar da interação, a qual encontra-se sujeita à variações sociais, culturais, ideológicas, geográficas, dentre outras, pois se a língua varia, os gêneros também variam, adaptando-se e renovando-se continuamente nas tensões entre a tradição, o estável, que permite identificar, por meio da inserção na história, as características recorrentes de determinados gêneros, e o novo, que é passível de mudança, de variações, daí o porquê dos gêneros do discurso serem relativamente estáveis.

Em outras palavras, de acordo com Bakhtin (2003), o processo de constituição dos gêneros do discurso não é algo extremamente fixo e imutável, 
mas sim um processo interativo entre o estável e o mutável, pois este processo é composto por forças centrípetas, que mantêm a estabilidade, as características tradicionais dos gêneros, e por forças centrífugas, que são os pontos de fuga, de mudanças, de variações possíveis em torno dos gêneros do discurso.

As tensões entre a tradição e o novo são essenciais para a concepção de gênero do discurso, pois, como afirma Bakhtin (2003), se os gêneros não existissem, se nós não os dominássemos e, em consequência, tivéssemos que criá-los sempre que fôssemos enunciar, no processo da fala e da escrita, seria quase impossível a interação por meio da língua.

Para Bakhtin (2003), os gêneros do discurso se dividem em primários (simples) e em secundários (complexos - romances, dramas, pesquisas científicas, artes, e outros). Durante o processo de formação, os gêneros secundários, mais desenvolvidos e organizados, incorporam e reelaboram vários gêneros primários - que se formam em situações de comunicação imediatas -, o que demonstra a extrema variedade e heterogeneidade dos gêneros discursivos.

Destarte, a partir da teorização explicitada podemos caracterizar as histórias em quadrinhos como um gênero do discurso, como um tipo relativamente estável de enunciado. E é por apresentar essa característica relativamente estável que podemos observar o uso do gênero $\mathrm{HQ}$, para abordar assuntos não ficcionais, como é o caso do corpus para nossa análise, $O$ incrível mensalão, de Angeli, que retrata a temática política.

Contudo, antes de partimos para a análise, é importante discutirmos sobre o gênero do discurso história em quadrinhos.

\section{História em quadrinhos}

As histórias em quadrinhos (doravante HQs) florescem no final do século XIX, devido à ambientação favorável ao seu surgimento como comunicação de massa, como a evolução da indústria gráfica e o aparecimento 
de grandes cadeias jornalísticas, fatores que tornam possível uma maior e mais rápida disseminação, transmissão dos quadrinhos, em meio impresso, o que facilitou também a agilidade, a distribuição e as vendas das HQs.

Após a Segunda Guerra Mundial (1939 a 1945), cresce a popularidade das histórias em quadrinhos com o aparecimento de heróis ficcionais no conflito bélico e, posteriormente, surgem os gêneros de terror e suspense, que dão continuidade à popularidade entre o público juvenil e adulto, pois as HQs representam de maneira lúdica e patriotista a defesa da ordem e da justiça no período social, histórico e ideológico vivido pelos adolescentes e jovens da época.

Entretanto, durante o período de pós-guerra e início da Guerra Fria, o psiquiatra alemão naturalizado americano, Fredric Wertham, em seu livro intitulado Seduction of the Innocent (Sedução do Inocente), em 1954, faz a associação da leitura de HQs aos casos patológicos de jovens e adolescentes problemáticos (RAMA; VERGUEIRO, 2008). Obra que causou um rebuliço nos Estados Unidos e influenciou a campanha para a censura das publicações dos quadrinhos.

Diante da campanha negativa em torno das HQs e apesar da imensa popularidade entre crianças, jovens e adolescentes, a leitura das histórias em quadrinhos passa a ser estigmatizada pelas camadas ditas "pensantes" e "cultas" da sociedade, pois acredita-se, em consonância com Rama e Vergueiro (2008, p. 16), que

[...] sua leitura afastava as crianças dos objetivos "mais nobres" como o conhecimento do "mundo dos livros" e o estudo de "assuntos sérios" -, que causavam prejuízos ao rendimento escolar e poderia, inclusive, gerar consequências ainda mais aterradoras, como 0 embotamento do raciocínio lógico, a dificuldade para a apreensão de idéias abstratas e o mergulho em um ambiente imaginativo prejudicial ao relacionamento social e afetivo de seus leitores.

Assim, as histórias em quadrinhos são vistas como geradoras de "preguiça mental" nos leitores e os afastam da chamada "boa leitura" 
(VERGUEIRO; RAMOS, 2009, p. 9). Argumentos desprovidos de embasamento científico e que demonstram um desconhecimento acerca da área (HQs).

Will Eisner (2001) utiliza o termo arte sequencial para descrever as histórias em quadrinhos. Para o autor a função fundamental da arte dos quadrinhos é:

[...] comunicar ideias e/ou histórias por meio de palavras e figuras, envolve o movimento de certas imagens (tais como pessoas e coisas) no espaço. Para lidar com a captura ou encapsulamento desses eventos no fluxo da narrativa, eles devem ser decompostos em segmentos sequenciados. Esses segmentos são chamados de quadrinhos (EISNER, 2001, p. 38).

Em outras palavras, as histórias em quadrinhos são, predominantemente, dispostas em pequenos quadros organizados em sequência e possuem como objetivo narrar ideias e/ou histórias, geralmente ficcionais $^{2}$, de variadas temáticas situadas em determinados momentos sociais, históricos e ideológicos, por meio do uso das linguagens verbal (palavras) e não verbal (imagens). Tem-se assim, de acordo com Vergueiro (2011), na linguagem gráfica sequencial, a relação entre o código escrito e imagético que permitem uma fruição única de leitura.

A configuração geral das histórias em quadrinhos apresenta um entrecruzamento e uma indissociabilidade entre palavra e imagem, as quais exigem que o leitor exerça as suas habilidades interpretativas visuais e verbais mutuamente, pois ler HQs, como salienta Eisner (2001), é um ato de percepção estética e de esforço intelectual, que exigem de seus leitores um desempenho intelectual e estético durante a leitura concomitante do verbal e do não verbal.

No que tange à linguagem não verbal e verbal, é válido reiterar, segundo Eisner (2005), que a responsabilidade de se contar uma história em quadrinhos é tanto das palavras quanto das imagens, pois as HQs são compostas por imagens estáticas, desprovidas de sons e de movimentos, e por

\footnotetext{
${ }^{2}$ Conforme Lopes (2000), ficção pode ser fingir, encenar, criar, inventar. A definição exata dependerá da situação de uso do ficcional.
} 
esta razão cabe às palavras, à linguagem verbal, interagir com as imagens na produção dos efeitos de sentidos materializados nos quadrinhos.

Podemos estabelecer, em consonância com Ramos (2009a, 2009b), algumas "tendências", regularidades, do que venha a ser considerado HQs: (a) diferentes gêneros utilizam a linguagem dos quadrinhos; (b) há a predominância da sequência; (c) podem apresentar personagens permanentes ou não; (d) a narrativa pode ocorrer em um ou mais quadrinhos; (e) em muitas das vezes, o rótulo, o formato e o veículo de publicação constituem elementos que agregam informações ao leitor, orientando a percepção do gênero em análise; ( $f$ ) uso de imagens desenhadas ou fotografias.

Para Ramos (2009a, 2009b, 2011), as histórias em quadrinhos são consideradas como um grande gênero, que agrega diferentes outros gêneros, que possuem similitudes e algumas peculiaridades, como a charge, o cartum, as tiras cômicas e outros.

A charge é caracterizada como um quadrinho de humor, composto pelas linguagens verbal e não verbal, que aborda algum fato ou tema ligado ao noticiário, como acontecimentos políticos, sociais, educacionais, dentre outros, cujo intuito maior é o de representar de maneira crítica determinados assuntos, por meio das relações interdiscursivas com a notícia, com o acontecimento retratado.

O cartum, ao contrário da charge, não é vinculado a um fato específico do noticiário, o humor advém de situações corriqueiras e cotidianas, situações inicialmente banais e rotineiras, que provocam o humor e/ou a sensibilização, em muitos casos, pela obviedade das situações e atitudes do ser humano.

O gênero tira cômica é caracterizado por textos curtos, com personagens fixos ou não, que criam uma narrativa com desfecho inesperado no final, atrelado ao humor. A tira cômica ou tira em quadrinhos recebe este nome devido à sua composição, ao seu formato. As tiras são veiculadas em jornais, sites e em livros e, normalmente, são compostas por três quadros.

No que se refere ao corpus de análise, atualmente é perceptível o crescente uso das histórias em quadrinhos para a elaboração de matérias 
jornalísticas, neste caso, relacionada ao mensalão. Temáticas essas destinadas, na maioria das vezes, a outros gêneros do discurso, como o artigo científico, o artigo de opinião, dentre outros, nos quais prevalecem, predominantemente, 0 uso da linguagem verbal e formal.

Essa assertiva nos leva a crer que o uso dos quadrinhos para a veiculação de assuntos não ficcionais auxilia a compreensão de dados efeitos de sentidos por parte dos leitores. Fato que demonstra também que atualmente os quadrinhos têm ganhado espaço de destaque na sociedade, o que pode demonstrar visões menos preconceituosas com relação ao gênero.

Na sequência, a partir da HQ O incrível mensalão, de Angeli, problematizamos o porquê do uso do gênero do discurso história em quadrinhos para a abordagem de assuntos não ficcionais.

\section{Reflexões sobre o gênero história em quadrinhos: 0 incrível mensalão}

A história em quadrinhos intitulada $O$ incrível mensalão, publicada no Jornal Folha de São Paulo, no dia 19 de agosto de 2012, é composta por doze páginas e tem como arte: Angeli, roteiro: Mario Cesar Carvalho e edição: Diogo Bercito. Em linhas gerais, o assunto abordado é de cunho não ficcional, cujo foco é o crime financeiro conhecido por mensalão, que possui grande relevância social, pois, relaciona-se ao âmbito político brasileiro e têm ganhado visibilidade maior nos meios midiáticos.

No transcorrer da história em quadrinhos há a contextualização dos fatos que retomam o início do escândalo - a denúncia, as motivações, o esquema e sua logística, dentre outros - até momentos anteriores ao julgamento do mensalão, fato de notoriedade no Brasil.

No primeiro quadrinho tem-se materializado que Do lodo, às vezes nasce uma flor de lótus. Mas, em outras, dali só sai mais lama mesmo. Assim, como os dizeres, as palavras são tecidas a partir de uma multidão de fios ideológicos e servem de trama a todas as relações sociais em todos os domínios (BAKHTIN, 2006), tem-se explicitado discursivamente a negatividade da 
narração a ser realizada e os valores ideológicos que perpassam a construção da HQ: política e lodo/lama têm sentidos correlatos.

A história sobre o mensalão inicia-se a partir da denúncia feita pelo deputado Roberto Jefferson ao Jornal Folha de São Paulo, em junho de 2005. No transcorrer dessa $\mathrm{HQ}$, tem-se a tentativa de explicar o caso do mensalão. Os personagens são construídos de maneira caricatural e representam os indivíduos envolvidos no fato, o que nos permite estabelecer aproximações entre o gênero $\mathrm{HQ}$ e a charge, pois, antigamente era apenas na charge que havia a ligação entre o assunto narrado, o noticiário e a construção caricatural de personagens. NO incrível mensalão tanto o assunto quanto os personagens são não ficcionais, o mensalão e seus protagonistas fazem parte do nosso contexto social e histórico: a sociedade brasileira contemporânea.

Em outros termos, na HQ os personagens Roberto Jefferson, Delúbio Soares, Marcos Valério, José Dirceu, José Genuíno, dentre outros, mesmo que de maneira caricaturada, são componentes da sociedade política e/ou empresarial do Brasil. Há personagens não ficcionais, ao contrário do que acontecia com frequência no gênero $H Q$, em que os personagens eram ficcionais e, no máximo, eram inspirados em alguém.

As temáticas mobilizadas na construção da HQ remontam a corrupção que envolve os meios político e empresarial, a lavagem de dinheiro, o repasse indevido de dinheiro público, (re)eleições duvidosas, CPIs, infidelidades partidárias e outros, fatos esses materializados em documentos sobre 0 mensalão. NO incrível mensalão os dizeres dialogam historicamente e ideologicamente com outros dizeres relacionados à política e à sociedade, cuja conotação ideológica explicita valores negativos e rotineiros sobre o que é fazer política no Brasil. Contudo, quando pensamos em valores ideológicos, é possível observamos que a conotação negativa não é para todos, pois, é porque há pessoas que não consideram como grave o crime financeiro conhecido por mensalão, que se instaurou o julgamento. Conforme a afirmação já referida anteriormente de Bakhtin (2006, p. 67), "cada palavra se apresenta como uma arena em miniatura onde se entrecruzam e lutam os valores sociais de 
orientação contraditória", o que possibilita valores sociais contraditórios acerca do mensalão - alguns condenam com afinco tal prática e outros não.

Angeli para validar os discursos materializados durante a construção da história em quadrinhos sobre o mensalão explicita ao término que todas as informações e os diálogos reproduzidos nesse caderno foram extraídos de entrevistas, documentos e testemunhos que fazem parte do processo do mensalão. Dessa forma, dizeres anteriores sobre o mensalão são selecionados e retomados para a construção da $\mathrm{HQ}$, levando em consideração o que pode e deve ser dito nesse dado momento. Tal assertiva também tenta repassar aos eventuais leitores uma pretensa imparcialidade com relação aos fatos apresentados, uma vez que a narração se baseia em um assunto não ficcional.

Logo, se as falas materializadas na HQ são recortes do processo, como atesta Angeli, tem-se uma montagem discursiva e quem monta - nesse caso, 0 quadrinhista -, reconstrói o fato narrado a partir de dado posicionamento ideológico. Ou seja, devido às escolhas estilísticas, há na $\mathrm{HQ}$ a materialização dos valores ideológicos que são constitutivos tanto dos sujeitos enunciadores quanto do jornal, pois, de acordo com Bakhtin (2006), a língua é uma atividade essencialmente dialógica, na qual os sujeitos interagem em dados momentos sociais, históricos e ideológicos.

Tem-se assim, os respectivos enunciados que dão conta do discurso oficial e o comentam, isto é, enunciados relatados e enunciados sobre o enunciado materializados, principalmente, no processo do mensalão e no Jornal Folha de São Paulo.

No que tange à escolha do gênero $\mathrm{HQ}$ para falar sobre o mensalão, nos indagamos "Por que há o uso da história em quadrinhos pelo veículo Folha de São Paulo e não outro gênero em seu lugar?".

A nosso ver, ao utilizar o gênero do discurso história em quadrinhos não ficcional para abordar $O$ incrível mensalão tem-se uma tentativa de explicitar, por meio das linguagens verbal e não verbal, a complexidade do mensalão, seus protagonistas, sua estruturação e suas implicações para a sociedade brasileira, isto é, expor didaticamente assuntos de extrema 
importância social, os quais, por vezes, podem ser pouco ou não compreendidos pelos leitores, pelos cidadãos de diversas faixas etárias adolescentes, jovens e adultos - que são leitores do jornal e, possivelmente, têm interesse nas notícias que circundam pela nossa sociedade.

Para tal objetivo inicial - facilitar a compreensão - o gênero HQ é bastante produtivo, pois, utiliza a linguagem verbal e não verbal, isto é, duas formas de linguagem se complementam na materialização dos dizeres, o que auxilia na compreensão da história narrada. Tem-se também uma relação intimista com o leitor, pois, ao utilizar imagens, o interlocutor tende a ler com maior segurança e prazer a $\mathrm{HQ}$, logo, há relações dialógicas entre o leitor e o gênero, e ambos são constituídos na heterogeneidade. O leitor constituído pela heterogeneidade de vozes - polifonia - que permeiam os seus dizeres e os dizeres dos outros. E o gênero constituído por diversos discursos, que retomam incessantemente outros discursos, o que caracteriza o dialogismo, na teoria bakhtiniana.

Em outras palavras, tem-se um o uso do gênero do discurso HQ para abordar temáticas não ficcionais, pois, anteriormente, os assuntos não ficcionais eram, na maioria das vezes, destinados a outros gêneros do discurso, como o artigo científico, o artigo de opinião, dentre outros, nos quais prevalecem, predominantemente, o uso da linguagem verbal e formal. Gêneros esses que foram consagrados, ao longo de vários anos, como adequados para a veiculação de assuntos não ficcionais e considerados sérios pela sociedade.

Assim, o gênero do discurso HQ não ficcional ao somar linguagem verbal e não verbal facilita a compreensão de dados efeitos de sentidos. Há então, o uso das HQs como forma de convencimento, isto é, tem-se um jogo em torno de quem diz (Angeli / Jornal Folha de São Paulo), o quê se diz (o mensalão), para quem se diz (leitores do jornal impresso e/ou on-line), em condições sociais, históricas e ideológicas (cenário político brasileiro contemporâneo), cujo objetivo é o convencimento do interlocutor da HQ acerca da provável veracidade dos fatos apresentados. 
Esse uso do gênero HQ não ficcional é possível devido ao fato de que, segundo Bakhtin (2003), o processo de constituição dos gêneros do discurso não é algo extremamente fixo e imutável, mas sim um processo interativo entre o estável e o mutável, pois esse processo é composto por forças centrípetas, que mantêm a estabilidade, as características tradicionais dos gêneros, e por forças centrífugas, que são os pontos de fuga, de mudanças, de variações possíveis em torno dos gêneros do discurso. Ou seja, as forças centrípetas mantêm as características do que é o gênero $\mathrm{HQ}$ - relação entre o verbal e o não verbal, arte sequencial, personagens ficcionais e outros - e as forças centrífugas possibilitam a transformação, a mudança, neste caso específico, a possibilidade de abordagem de temáticas e personagens não ficcionais, como 0 caso do mensalão.

Portanto, em consonância com Bakhtin (2006, p. 44) "cada época e cada grupo social têm seu repertório de formas de discurso na comunicação socioideológica", isto é, na sociedade contemporânea brasileira - verbal e maciçamente visual, imagética - tem-se a possibilidade de uso das histórias em quadrinhos para a abordagem de assuntos não ficcionais.

\section{Efeito de conclusão}

Após as análises e as problematizações feitas acerca do gênero do discurso história em quadrinhos não ficcional com foco nO incrível mensalão, de Angeli, é possível observarmos que esse gênero vem sendo utilizado com maior frequência por conta da nossa intensa e constante relação com o outro, com a história, com os efeitos de sentidos diversos. Esse uso do gênero HQ não ficcional reforça a interação com o outro, o dialogismo com o outro via discurso, e nos possibilita observar que os sentidos são múltiplos e a ideologia é inerente à palavra, ao discurso.

Podemos também observar as relações entre as forças centrífugas, que mantêm a estabilidade, e as forças centrífugas, que permitem transformações do gênero história em quadrinhos, por isso, como atesta Bakhtin (2003), os 
gêneros do discurso são tipos relativamente estáveis de enunciados. Ou seja, os gêneros são dinâmicos, no sentido, de serem moldáveis pelos interlocutores inseridos em dados contextos sociais, históricos e ideológicos, e possuem também características/formas predominantes, pré-estabelecidas historicamente, por meio de convenções linguísticas e/ou literárias, que permitem a identificação e a percepção de dadas peculiaridades frente à heterogeneidade de gêneros existentes na sociedade.

Atualmente, podemos verificar a reiterada aceitação do público (infantil e/ou adulto) às histórias em quadrinhos. Aceitação de um gênero que utiliza linguagem verbal e não verbal, pois, vivenciamos uma era em que o visual, as imagens, ganham cada vez mais força e se completam com as palavras, fato observado nos contemporâneos recursos tecnológicos - filmes 3D, internet, blogs, redes sociais, computadores/celulares modernos, lousas interativas, nos quais o apelo visual, imagético é crescente.

Diante dessa era digital e extremamente visual, o gênero história em quadrinhos ganha ainda mais adeptos ao materializar fatos importantes por meio de palavras e imagens. O uso da $\mathrm{HQ}$ não ficcional concilia o prazer em ler histórias, imagens, com a necessidade de conhecer a história de seu país, de seu mundo, de sua sociedade, e mais que isso, incentiva a necessidade de refletir e agir sobre os acontecimentos que nos circundam cotidianamente.

Esperamos que a temática exposta em nosso artigo, embasada nas obras de Bakhtin, Eisner e outros, possibilite futuras abordagens teóricas e que novas problematizações acerca do uso das histórias em quadrinhos para a abordagem de assuntos não ficcionais sejam pesquisadas, debatidas e acrescidas ao nosso cotidiano, principalmente, acadêmico e escolar.

\section{Referências}

BAKHTIN, Mikhail. Estética da criação verbal. Tradução de Paulo Bezerra. São Paulo: Martins Fontes, 2003. 
BAKHTIN, Mikhail. Marxismo e filosofia da linguagem: problemas fundamentais do método sociológico na ciência da linguagem. 12. ed. São Paulo: Hucitec, 2006.

CARVALHO, Mario Cesar. O incrível mensalão: a história do super-escândalo que abalou o mundo político e fez tremer o governo Lula. Folha de São Paulo, São Paulo, 19 ago. 2012. Disponível em: <http://www1.folha.uol.com.br/ fsp/poder/61728-o-incrivel-mensalao.shtml>. Acesso em: 26 ago. 2012.

DENZIN, Norman K.; LINCOLN, Yvonna S. A disciplina e a prática da pesquisa qualitativa. In: DENZIN, Norman K.; LINCOLN, Yvonna S. O planejamento da pesquisa qualitativa: teorias e abordagens. Tradução de Sandra R. Netz. Porto Alegre: Artmed, 2006. p. 15-41.

DUFFY, Brendan. Análise de evidências documentais. In: BELL, Judith (Org.). Projeto de pesquisa: guia para pesquisadores iniciantes em educação, saúde e ciências sociais. Tradução de Magda F. Lopes. 4. ed. Porto Alegre: Artmed, 2008. p. 107-117.

EISNER, Will. Narrativas gráficas. Tradução de Leonardo Luigi Del Manto. São Paulo: Devir, 2005.

EISNER, Will. Quadrinhos e arte sequencial. São Paulo: Martins Fontes, 2001.

FAÏTA, Daniel. A noção de "gênero discursivo" em Bakhtin: uma mudança de paradigma. In: BRAIT, Beth (Org.). Bakhtin, dialogismo e construção do sentido. 2. ed. Campinas: Unicamp, 2005. p. 149-168.

FERNANDES, Cristiana de Almeida. Mauricio de Sousa: construção de personagens de ficção $x$ construção de personagens de não-ficção. Revista Práxis, Volta Redonda, ano 2, n. 4, p. 41-44, ago. 2010. Disponível em: <http://www.foa.org.br/praxis/numeros/04/41.pdf>. Acesso em: 27 out. 2012.

FIORIN, José Luiz. Categorias de análise em Bakhtin. In: PAULA, Luciane; STAFUZZA, Grenissa (Org.). Círculo de Bakhtin: diálogos (in) possíveis. Campinas: Mercado de Letras, 2010. p. 33-48.

KOCH, Ingedore G. Villaça. Desvendando os segredos do texto. 6. ed. São Paulo: Cortez, 2009.

LOPES, Emília Mendes. O discurso ficcional: uma tentativa de definição. 2000. 134 f. Dissertação (Mestrado em Letras) - Belo Horizonte Faculdade de Letras da UFMG, 2000.

PIRES, Maria da Conceição Francisca. Cultura e política nos quadrinhos de Henfil. História, São Paulo, v. 25, n. 2, p. 94-114, 2006. Disponível em: <http://www.scielo.br/pdf/his/v25n2/04.pdf>. Acesso em: 28 ago. 2012. 
RAMA, Aangela; VERGUEIRO, Waldomiro (Org.) Como usar as histórias em quadrinhos na sala de aula. São Paulo: Contexto, 2008.

RAMOS, P. Tiras, gênero e hipergênero: como os três conceitos se processam nas histórias em quadrinhos?In: SIMPÓSIO INTERNACIONAL DE ESTUDOS DE GÊNEROS TEXTUAIS, 6., 2011, Santa Maria. Anais... Santa Maria, 2011. Disponível em: <httpwww.cchla.ufrn.brvisiget>. Acesso em: 22 mar. 2012.

RAMOS, Paulo. A leitura dos quadrinhos. São Paulo: Contexto, 2009a.

RAMOS, Paulo. Histórias em quadrinhos: gênero ou hipergênero. Estudos Linguísticos, São Paulo, v. 38, n. 3, p. 355-367, set./dez. 2009b. Disponível em: <http://www.gel.org.br/estudoslinguisticos/volumes/38/EL_V38N3_28.pdf>. Acesso em: 5 set. 2010.

SAUSSURE, Ferdinand. Curso de linguística geral. Tradução de A. Chelini, J. P. Paes e I. Blikstein. São Paulo: Cultrix, 1977.

VERGUEIRO, Waldomiro. Prefácio. In: SANTOS NETO, Elydio; SILVA, Marta Rregina Paulo (Org.). Histórias em quadrinhos \& educação: formação e prática docente. São Bernardo do Campo: Universidade Metodista de São Paulo, 2011. p. 7-9.

VERGUEIRO, Waldomiro; RAMOS, Paulo. Quadrinhos na educação: da rejeição à prática. São Paulo: Contexto, 2009.

VIANA, Nildo. Quadrinhos e política. 2011. Disponível em: <http://www.bocc.ubi.pt/pag/viana-nildo-quadradinhos-e-politica.pdf>. Acesso em: 28 ago.2012. 